\title{
REPRESENTATIONS OF LOCAL IDENTITY THROUGH LANDMARKS: THE REHABILITATION OF RUPEA FORTRESS, ROMANIA
}

\author{
Zoltan MAROȘI \\ Babeş-Bolyai University, Cluj-Napoca, Faculty of Geography, ROMANIA \\ Centre for Research on Settlements and Urbanism \\ zoltan_marosi@yahoo.de \\ DOI: http://doi.org/10.23740/TID120173
}

ABSTRACT

Over the centuries a community's built heritage was shaped according to the members' needs and skills, using the available resources, making it comparable to a palimpsest on which the evidence of every change was preserved in distinct layers. Based on historical documents, illustrations and recent observations, the purpose of this approach is to increase the level of understanding and preservation of historical monuments with their rich cultural significance, using as an example the less known, recently rehabilitated Rupea Fortress, in Brașov County. It is clear that the rehabilitation was focused exclusively on the technical side, proved by the lack of a well managed tour guide system with authorised guides and the lack of additional studies to the main project, making this approach well timed. The basalt cliff on which the fortress was strategically built is also a natural monument (IUCN Category III), considered as a geological heritage itself, increasing the uniqueness of this representative historic site. The distinctive perceptual skyline of this landmarks is part of the collective memory, local history and identity which justifies all the conservation and research efforts for the future generations, as part of long-term and sustainable development.

Keywords: rehabilitation, fortifications, local identity, Rupea Fortress

\section{INTRODUCTION}

A strong sense of belonging to a place was the past generations' source of determination and strength and the only needed argument to justify their constant effort to defend their land, measures whose traces are still preserved today, having historical significance, associated with events and personalities. It is always more than just walls and landscapes and Rupea is not an exception as shown in this old testimony: "The more I saw of these places, and thought of their origin, the more extraordinary did they appear" (Boner, 1865, p. 246). According to Feilden $(2003$, p. 1), every historical building has a message, "a complexity of ideas and of cultures may be said to encircle a historic building and be reflected in it."

In our case, a historic building or monument should be understood as a building which arouses one's interest, through an emotional impact, "and makes us want to know more about the people and culture that produced it" (Feilden, 2003, p. 1). The etymology of the monument, as Curinschi-Vorona (1996, p. 19) explains, originates from the Latin monumentum, meaning memory, remembrance, from the Latin verb moneo-ere, "to remind", expressing the cognitive value of monuments and their ability to preserve people's memory. The attribute historic can be given to a monument to enrich its meaning, to emphasize its age, as Feilden $(2003$, p. 1$)$ concludes: "if it has survived the hazards of 100 years of usefulness, it has a good claim to being called historic." A landmark is distinguished by its visibility and, usually refers to a monument. 


\section{Rehabilitation, restauration or conservation?}

Choosing the word rehabilitation instead of restoration in the project title: "The Rehabilitation and Expansion of the Tourism Infrastructure in the Town of Rupea" (Stimulating the Economic Development in the Region of Rupea by Harnessing the Touristical Potential) was not without a reason. According to Oxford Online Dictionaries, rehabilitation is the action of restoring someone to health or to former privileges and also refers to restoring something that has been damaged to its former condition. According to Feilden (2003, p. 10), rehabilitation of "buildings as opposed to objects is to keep them in use - a practice which [...] may involve modernization with or without adaptive alteration." This word is more permissive than restauration which focuses on the original condition of something material, by preserving and recovering the original features with the minimal intervention of modern methods and techniques. Both actions, rehabilitation and restauration, have the same objective, but the methods are different, making the results easily distinguishable. Furthermore, a successful restoration complies with the existing laws and principles, including the Principle of Minimum Intervention, which is always the best. Thus, if possible, the action should be reversible and not prejudice possible future interventions. The ethics of conservation, as Feilden $(2003$, p. 6$)$ describes, should be rigorously observed and applied by all the specialists that work together in restauration, the presented standard of ethics including the following: (1) recording the building condition before any kind of intervention; (2) historic evidence must not be destroyed, falsified or removed; (3) any intervention should observe the building aesthetics, historical and physical integrity; (4) all materials and methods used during the intervention must be fully documented and (5) the interventions should be reversible or at least repeatable. Curinschi-Vorona (1996, p. 17) associates with restoration (also valid for rehabilitation) the following notions: maintenance, consolidation, renovation, refunctionalisation, remodeling, and regeneration.

Conservation is limited to the minimum necessary interventions to maintain a building or a cultural artifact in its existing condition, slowing down further deterioration, without major structural interventions. This action stands for sustainable and long-term development for the future generations and is a common practice in the world's museums. Conservation may also refer to buildings, resources, ecosystems, wildlife, water, and others. When a historic building is in conservation, the first concerns, also shown by Beckmann and Bowles (2004, pp. 37-51), are to examine the building records and documentations if they exist. Every historic document or illustration with the particular structure should be carefully examined. Gathering all the information about the building should reveal the stages of renovation and expansion carried out in the past and even past techniques, materials and various other information about the group mentality of those who built the building. Therefore, historic buildings are important artifacts which, in most cases, are a representation of the local identity.

The concepts rehabilitation, restauration and conservation rely on complex multidisciplinary approaches among which architecture has the largest share. Even so, an architect alone cannot cover the whole complexity of a successful restoration, therefore a complete team should consist of archaeologists, historians, archivists, construction and structural engineers, chemists specialised in restoration, painters, urban planners and, sometimes, even urban geographers. The architect is the most appropriate to coordinate such a team, but not without a thorough specialisation in restoration: "[...] the architect must educate himself to understand the arthistorical and archaeological importance and character of the particular structure with which he is concerned, and develop a sensitivity towards the preoccupations of the different groups and disciplines interested in its continued preservation" (Bristow, 2006, p. 8). 


\section{METHODOLOGY}

The research in the field of restorations, as in urban planning, often lean toward flexible and adaptable methodologies. The great variety of buildings and their uniqueness lead to the necessity of personalisation, using and combining more methods to obtain better results. This approach of the complex reality, using multiple methods in combination, adapted for specific situations, is described by Sposito and Faggian $(2013$, p. 2) as a "multimethodology, mixing and matching methods". This research, focused on urban planning and local identity, describes the theory of an History and Archaeological Study as part of urban planning documentations. The most common questions about the purpose and drafting of such a study are: (1) Which are the official documentation sources? (2) What contains an History and Archaeological Study? (3) How this study is relevant in urban planning? and (4) Which are the overall objectives?

\section{Official documentation sources}

Regardless of where the research takes place, there are several administrative offices which are responsible by law for monuments and urban planning. Collecting data from these offices is done under contract, most often with the company that produces this kind of studies. Most often, experts in various fields, with signature rights, process the data under the supervision of the chief architect. In Romania, the relevant offices for a History and Archaeological Study are the following: The Regional Councils, The Local Town Halls, The Regional Departments of Culture, The National Agency for Cadastre and Land Registration, The National Archaeological Repertoire and The List of Historical Monuments of Romania (LMI 2015) edited by The Romanian National Institute for Historical Monuments, part of The Ministry of Culture in Romania. For example Rupea Fortress is registered on the list between numbers 759-762, with the code BVII-a-A-11769, with information about the rank of the monument (Table 1).

Table 1: Extract from the List of Historical Monuments of Romania, LMI 2015

\begin{tabular}{|l|l|l|l|}
\hline List no. & LMI 2015 Code & Monument & Date \\
\hline 759 & BV-II-a-A-11769 & Rupea Fortress (Cohalm's Fortress) & $14^{\text {th }}$ to $17^{\text {th }}$ century \\
\hline 760 & $\begin{array}{l}\text { BV-II-a-A- } \\
11769.01\end{array}$ & $\begin{array}{l}\text { The upper enclosure, with chapel and storage } \\
\text { spaces for provisions (partially preserved) }\end{array}$ & $14^{\text {th }}$ to $17^{\text {th }}$ century \\
\hline 761 & $\begin{array}{l}\text { BV-II-a-A- } \\
11769.02\end{array}$ & $\begin{array}{l}\text { The middle enclosure, with towers and storage } \\
\text { spaces for provisions }\end{array}$ & $14^{\text {th }}$ to $17^{\text {th }}$ century \\
\hline 762 & $\begin{array}{l}\text { BV-II-a-A- } \\
11769.03\end{array}$ & $\begin{array}{l}\text { The lower enclosure, with towers, the gate } \\
\text { tower, the water well and other annexes }\end{array}$ & $14^{\text {th }}$ to $18^{\text {th }}$ century \\
\hline
\end{tabular}

Edited by The Romanian National Institute for Historical Monuments, part of The Ministry of Culture of Romania. LMI Code, according to Law no. 422/2001, Order of Culture and Religions (MCC, in Romanian) no. 2682/2003 and Order of the Ministry of Transport, Constructions, and Tourism (MTCT, in Romanian) no. 562/2003: BV - Brașov County, II - monuments of architecture, a - historic ensemble, A - of national importance.

Besides the official information that makes up the golden line of the research, other documents, as historical illustrations, postcards, photographs, maps and even old beletristic books should be considered as valuable sources of information (Maroși, 2016, pp. 45-58). Searching for other documents is also encouraged by Beckmann and Bowles (2004, p. 39): "documents that may 
also be helpful are descriptions, whether contemporary or later, of the construction practices of the period when the structure was built." This kind of documents can be found in the local and regional archives, churches, museums, schools and even in private collections of historical illustrations and documents. Exceptional results can be found in the least suspected places, for example, Rupea Fortress described in Charles Boner's travel journal $(1865$, p. 244) as shown in the following fragment: "At a turn in the road you suddenly see before you, crowning the ridge on your left, strange, dark, uncouth shapes sticking up into the sky. [...] At first it is not easy to discover whether they are rocks or masonry, but at last you see that they are castle walls, which abruptly ending where the line of hills suddenly sink down into a hollow, produce that sharp line which at first so puzzled you. Then again, wall rises above wall in an ablique line winding round the eminence, swathing it, so to say, in its repeated folds. But it is only from this side and this particular point of view that it has so strangely wild character."

\section{Cartographic sources and drawings}

With the exception of local historical maps, which were made for the privileged towns, the first available and complete source of historical maps of Transylvania is the Josephinian Land Survey conducted from 1763 to 1787 . Other available historical maps can be found online, in scanned form, for the following years: 1806, 1916, 1978 (Romanian Topographic Maps 1:25.000) and 1998. The National Agency for Cadastre and Land Registration sells ortophotographs for detailed studies at large scales (1:1000). A free alternative for the expensive ortophotoplans are the Google Earth satellite images, including the timelapse tool, but with many restrictions of use. Covering a long period of time with historical maps and recent ortophotoplans allows an accurate reconstruction of how the settlement structures evolved and therefore a detailed settlement evolution map can be produced. Yet, before this important step of a History and Archaeological Study, a complete land parceling and zoning analysis is mandatory.

Drawings are essential for this kind of studies, the selective recording of information obtained from direct observation of the historical structure will ensure access to information from the comfort of the office for the whole research team. Drawings combine the advantages of direct and indirect observation and increase the research efficiency, as Bristow (2006, p. 18) points out: "Record drawings may, in any case, be a vital prelude in approaching repair, especially where renewals and alterations have been carried out in the past, and will enable a proper understanding by the architect of that historic masonry." Drawings can be considered a universal language, which completes the text and, therefore, "redrawings should fill the gaps caused by aging and also keep the historical information in circulation" (Maroși, 2016, p. 46). In our case, drawings with Bird's-eye and front view are more representative (Figure 1):
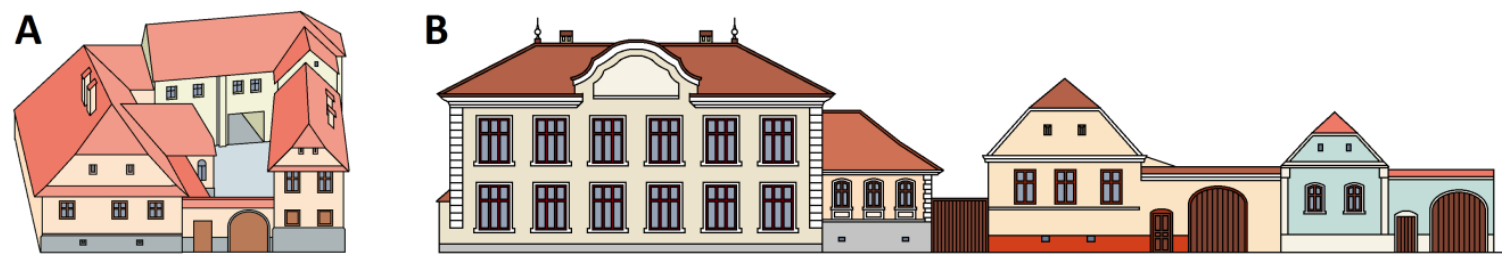

Figure 1: Typical historical buildings in the region of Rupea, A - Bird's-eye view, B - Front view 
Drawings, as well as maps, can be made at different scales, depending on the research type, but, most often, "[...] drawings show sections and elevations, generally of small enough scale that the whole of the building can be shown on one sheet" (Beckmann \& Bowles, 2004, p. 38). For a building 200 years old, the original drawings are not always available and, for rural areas, they are a rare luxury, which is why measuring and redrawing of architectural plans are a priority even if it is expensive. In exceptional cases, in which there are earlier drawings available, the first step should be an inspection to confirm that the building is in accordance with the original drawings (Beckmann \& Bowles, 2004).

\section{The relevance and objectives of a history and archaeological study}

Considering the large amount of information from various fields regarding the restauration or conservation of the built cultural heritage, the first purpose of the study should be to provide a clear transposition between laws, regulations, research, and technique. In other words, this kind of studies should build methodological bridges between local governments, multidisciplinary research teams, and other planning and engineering companies. Through the interdisciplinary nature of the approach, the experts should avoid generalising certain assumptions, therefore, another important objective of the study is welding different parts into an indestructible whole, which will gain new meaning and will ensure an effective and productive cooperation.

When completed, a History and Archaeological Study is usually signed by all the parties and experts who took part in drafting and becomes valid only after the approval of The Ministry of Culture. The minimum content and the approval procedures are specified through the regulations established by a specialised department of The Ministry of Culture. A complete study should include the following aspects: (1) the geographical demarcation of the area and the historical and cultural significance of the sites and monuments, (2) demographic evolution and spatial organisation of the investigated settlements, (3) results of the archaeological and geographical field research, (4) assessing the state of the sites and monuments, (5) detailed mapping of the studied area with the existing and proposed situation, (6) delimitation of specific protection zones for every historical site and monument, and (7) specification of urbanistic regulations, zoning rules including the Floor-Area Ratio (FAR) and the Building Coverage Ratio $(B C R)$. The entire process must be conducted observing the laws in force in order for the document to be validated by the ministry. Following and using data from official lists, as The List of Historical Monuments of Romania (LMI) and The National Archaeological Repertoire (RAN), is highly recommended. In our approach, we will analyse a single monument, which has a cultural significance for the town and region of Rupea, promoting the conduct of such studies.

\section{History and archaeological study as part of urban planning}

One of the main issues in modern Urban Planning and Design is to preserve local identities from globalization through a better management of the places and their built heritage. In this case the purpose of urban regulations is to maintain a balanced development by which historic buildings and places can be effectively conserved, restored and even functionally integrated in the urban ensemble. This issue is also underlined by Nasser (2003, pp. 467-468): "Within the context of planning in historic environments, a dichotomy exists between preserving the past for its intrinsic value and the need for development in response to changing societal values." For supporting these causes, History and Archaeological Studies are strongly encouraged to be conducted preliminary for every urban planning operation in historic places. Nevertheless, 
detailed urban zoning, which designates legal areas to permit and prohibit land uses are not always enough for the protection and conservation of historic places and buildings, a History and Archaeological Study should also be flexible and adaptable to particular situations. In urban practice, the delimitation of protection areas through lists of coordinates and mapping are very common, but considering the legislation, the process of identification and delimiting differs from country to country. Still, in the end, the general objectives are the same, to ensure a controlled and efficient development, involving smart solutions for the existing dysfunctions. Generally speaking, urban regulations are detailed for each delimited urban area (resulted after zoning), including the protection areas of monuments, sanitary protection zones, special protection areas of technical corridors, areas with total and temporary prohibitions for constructions and other functional areas and sub-areas (for example categorised residential sub-areas).

\section{RESULTS AND DISCUSSION}

Rupea is a small town, located in the centre of Romania (Brașov County, Transylvania) attested in documents since 1324 under the Hungarian name "Kőhalom" and the German name "Reps", the etymology of the names derives from "mound of rocks" or "cliff". The small town, with around 5,000 inhabitants, was since the $14^{\text {th }}$ century until 1876 the administrative centre of an old administrative area known as the "Kőhalom szék" (in Hungarian) and the "Repser Stuhl" (in German) one of the seven saxon administrative areas from Transilvania (Siebenbürgen). Rupea is characterised by a linguistic, ethnographical and religious mosaic (Ilovan \& Maroși, 2015, p. 64), with a typical architecture, culminating with The Fortress of Rupea, built strategically on the basalt cliff (a natural monument), which together form a perfect blend of natural beauty and human ingenuity and also a perfect case study for this research.

\section{The basalt cliff from Rupea as a natural monument}

A special geological structure, with an insular occurrence, is represented by the basalt cliff on top of which was built The Upper Fortress of Rupea, with a height of 582 meters above the sea level or 120 meters above the nearby town centre. There are many opinions regarding the origin of this unusual basalt cliff, including the fact that Rupea Fortress, the same as Deva Fortress, was built on a volcanic neck (exposed by the removal of surrounding rocks), which, due to the height and low accessibility, became a preferred strategic place (Irimuș, 2012, pp. 77-79). Another version claims that this cliff is part of a much larger complex of Quaternary basalts and rhyolites (the last eruptions of basalts in Romania), which are specific to a limited area of the nearby the Perşani Mountains. This geological area includes several natural monuments, such as: The Basalt Columns of Racoş, The Hegheș Volcanic Crater in Racoș, The Basalt Micro-canyon in Hoghiz, The Gorges of Dopca and The Basalt Cliff in Rupea. Regarding the similar chemical composition and age of these basalts $(1.5-1.7 \mathrm{Ma})$ and the relatively short distance between them (max. $10 \mathrm{~km})$, it is possible that they are part of the same geological area (Mutihac, 1990, p. 163). Among the most incredible events related to The Basalt Cliff in Rupea, dating back to 1976, was the town systematisation plans (urban planning under the communist regime), through which local authorities took into consideration the economic value of the basalt cliff and the possible source of cheap cobblestones for the unpaved streets in the town. Fortunately, there have been historians and local people who opposed the demolition of Rupea Fortress ruins and the plan was never implemented. At the beginning of the $3^{\text {rd }}$ millennium, the cliff received the status of a designated protected area, natural monument (IUCN Category III), with an area of 9 hectares of which 5 hectares occupies the exposed cliff (Law no. 5/06.03.2000) 
Historical depictions of Rupea Fortress

Rupea Fortress (Figures 2 and 3) appears in historical illustrations and literary descriptions.

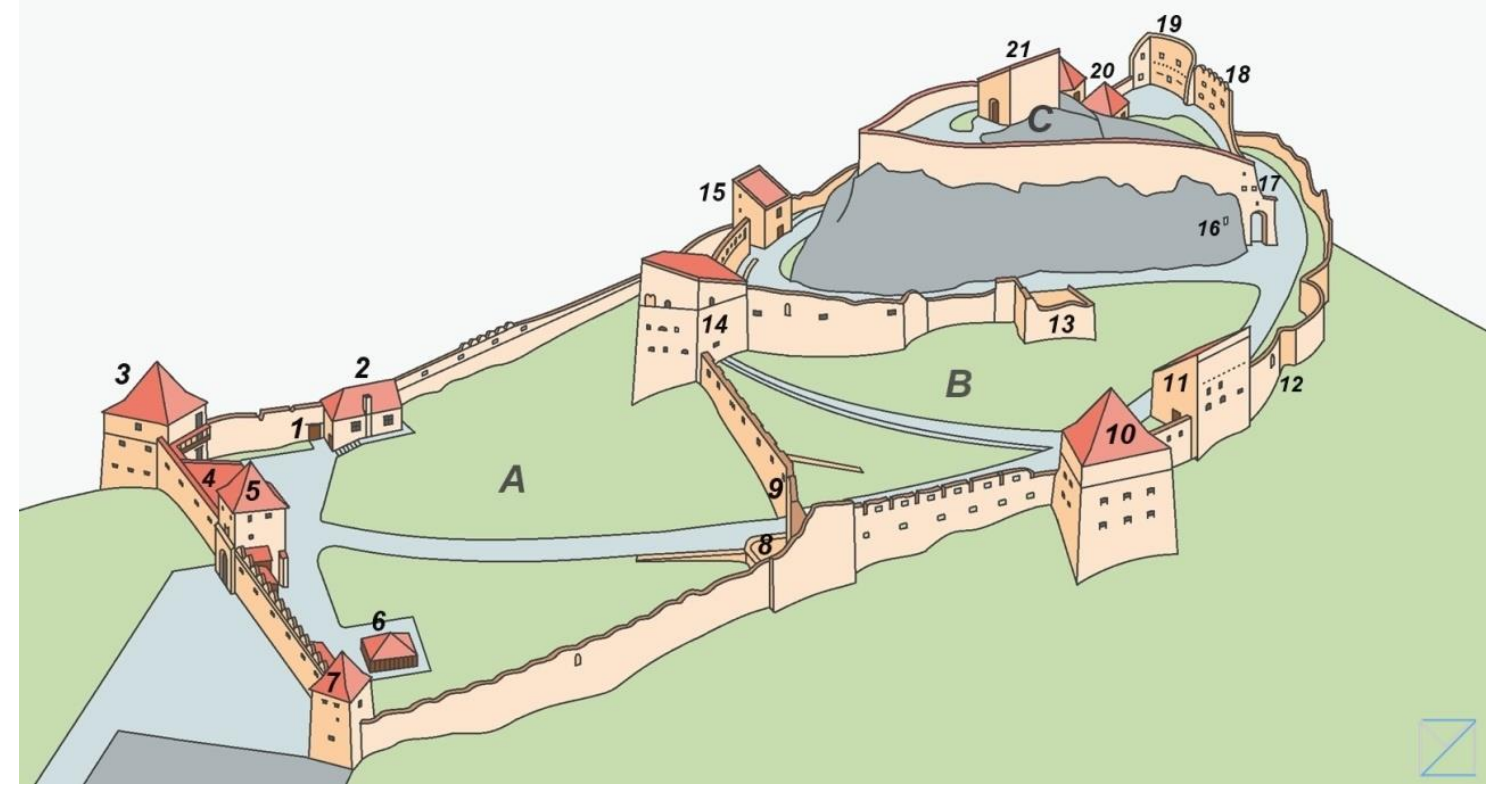

Figure 2: Bird's-eye view drawing of Rupea Fortress in its current form (west side) Drawing by MAROȘI Zoltan, 2016

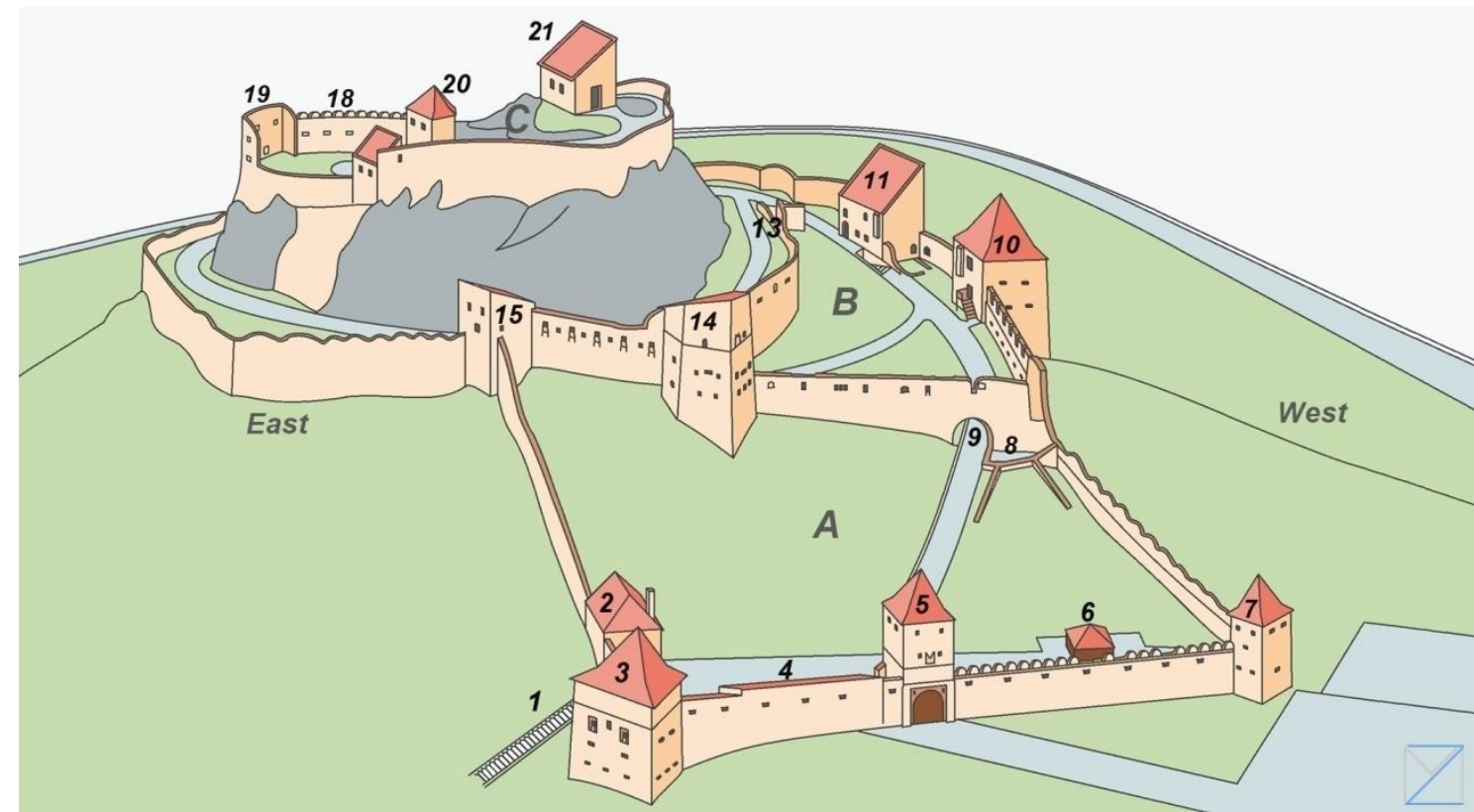

Figure 3: Bird's-eye view drawing of Rupea Fortress in its current form (north side) Drawing by MAROȘI Zoltan, 2016

1. Pedestrian entrance on the west side 2. The Guardian's House 3. The Lard \& Bacon Tower 4. Military warehouse 5. The Main Gate Tower 6. The water well 7. The Servants' Tower 8. The Galt's Tower 9. The Middle Fortress Gate 10. The Gresbig Tower or Scouts' Tower 11. Chapel 12. The Scouts' Secret Gate 13. The Thickened Tower 14. The Pentagonal Tower 15. The Scribes' Tower 16. Inscription in marble 17. The Upper Gate and Tower 18. Barracks 19. The Regional Administrative Chambers 20. Preserved private houses from the $17^{\text {th }}$ century 21. The Upper Chamber or The Watchmen's House A. The Lower Fortress B. The Middle Fortress and C. The Upper Fortress 
Among these, Ludwig Schuller's lithography Reps (1851) is one of the most important and accurate representations of the town central square (then a market place, today a park) and in the background, in a dominant position, the Fortress of Rupea. Among the literary descriptions, Charles Boner's travel journal (1865) is the most detailed: "The whole is of considerable extent, and must have been of great strength. For besides the steepness of the site, the high walls rising one behind the other at distant intervals would have made it difficult to gain an entrance. [...] it was not well possible to say where nature ended and where the work of men's hands began. Once within the precincts, you wound your way upwards as in the windings of a shell, stopped every now and then by a gateway, or what had been before" (p. 245).

\section{The cultural significance of Rupea Fortress}

The present shape of Rupea Fortress represents only a sketch of what it was a few centuries ago, the visitors can find traces of the original structures at every turn even without an authorised guide. It is obvious that the fortress rehabilitation focused exclusively on the technical side (Figure 6), the historical, archaeological and cultural significance was neglected, proved by the fact that years after the inauguration the fortress still does not have an authorised guide or a well organised and professional informative system. Often, the untouched ruins of the built heritage becomes very popular and known, not for their perfectly reconstructed white walls, but for their historical significance, associated with events and personalities, in which case the visitors are encouraged to reflect, to mentally reconstruct the ruins, developing new meanings and personal feelings related to that specific place. Outstanding examples of personal impressions about the fortress (now a century and a half old) were written by Boner (1865, p. 245): “(...) yet after examining such a place and nothing its size and strength, its formidable defences, and taking thought of what labour the work must have cost, fresh surprise awakes in us when we think that all this was planned and done by a few agricultural settlers." At that time, the fortress was in a neglected condition.

The way upwards to the fortress should arouse the visitor's desire to relive glimpses of the past, passing the intimidating gates should be followed by admiration, curiosity, and impressions. However, creating the required stimulation and atmosphere for the targeted effect is far more than rebuilding (using modern tehniques) an old wall. Unfortunately, Rupea Fortress rehabilitation has diminished the historic atmosphere. Inside the fortifications, it is created more the impression of a public place in which the common benches and the geometrically cut and cloned trees are in contrast with the original functions of the place. It is a lack of "visual order of unity, proportion, scale, contrast, balance, rhythm. Ornament and decoration also have the capacity to unleash feelings, trigger reactions, feed the memory and stimulate the imagination" (Moughtin et al., 1999, p. 3).

The pedestrian entrance to the fortress (Figure 2.1) was built in the $17^{\text {th }}$ century and, before the rehabilitation, it was used by tourists and locals, for direct access from the town centre. Today it is not used, but the massive wooden gate overlaid with metal strips is preserved in its original form, being one of the oldest wooden structures from the fortress. The gate also preserves the mechanism of the original lock and the fortress keys. Near this secondary gate, was built, in 1850 (probably on the site of another structure), The Guardian's House (Figure 2.2), which was used before the rehabilitation by the fortress key holders, and, afterwards, by security guards and staff members. The Main Gate Tower (Figure 3.5) is used today to enter The Lower Fortress (Figure 2.A), but before the rehabilitation, this gate was open only for carts and carriages, pulled by horses or oxen, and for important events. Considering the fact that the fortress had private 
buildings and even residents for a period of time, the gate was opened at certain times and on certain days. For example, families who had stored goods in the fortress, including flour, lard or wood, had access to their stock only on certain days per week. One of the storage places was The Lard \& Bacon Tower (Figure 3.3), a strong corner tower of the fortress, built with a basement and three levels. The internal wooden structure, with stairs and winches, was build to facilitate the storage of heavy goods, but, at the same time, the large firearms openings and other loopholes testify that it was a heavily armed bastion. The last floor was used for accommodation, when it was necessary, but also for storage. The name of this tower was given by the Saxon population which used the tower as a common storage of unrendered lard, bacon and other smoked meat products as food reserves, in case of a siege. Every family had a stamp which they used when they added or withdrew food, as a measure against theft.

Between the The Lard Tower and the Main Gate Tower, was built, in the $19^{\text {th }}$ century, a Military warehouse (Figure 2.4), but it was also used as a stable for horses. This recent building has replaced the original wall-walk between the two towers, but kept the firearms openings, which made the building defensive. On the other side of The Main Gate Tower, the covered wooden wall-walk was a direct access to The Servants' Tower (Figure 2.7), the original wooden structure had not been preserved, but, through reabilitation, it was partially reconstructed. The semicircular merlons of this wall (Figure 3 , between 5 and 7) are not the original ones, many unprofessional changes were made in 1973 during the shooting of the movie "Nemuritorii" [The Immortals] by Sergiu Nicolaescu, inside the fortress.

The Servants' Tower (Figure 2.7) is located in the northwestern corner of the fortress, slightly smaller than the other two towers from this alignment, but not less defensive. The town's official emblem was inspired by these three towers, represented on a blue shield with rounded edges (Decision of the Romanian Government no. 115/2013). The tower was probably used by stablemen and servants, in accordance with the fact that the extended area (approx. 4,100 $\mathrm{m}^{2}$ ) of The Lower Fortress was designed as a place to safely keep the cattles, horses, and other animals in case of a siege. The wealth of a family was reflected in the number of the owned animals and protecting them was not only for strategic reasons, but also for survival after a devastating invasion. It is possible that along the west wall of The Lower Fortress, there were several wooden stables, but their traces were lost in the last five centuries. The presence of the 42 meters deep water well (Figure 2.6), built in 1623, indicates that The Lower Fortress already existed, even if the towers are more recent. Solving the problem of the food and water stocks inside the fortifications was a great step forward, making the isolation and the starvationinducing sieges ineffective (tactics used in the previous Ottoman and Mongol invasions).

The Middle Fortress (Figure 2.B) was strategically designed as a second chance in case that The Lower Fortress would fall under a possible siege, making it possible for the defenders to retreat and prepare themselves for a new assault inside The Middle Fortress. This strategy is similar to the principles of the watertight compartments of a ship. It is clear that the protected natural position and the massive fortifications would increase considerably the resistance against any siege, but, without a direct source of water, the defenders and the population would remain vulnerable to military isolation. The Middle Fortress Gate (Figure 3.9) was built without a tower and the defence was made through the crenelated wall fitted with murder holes and loopholes. Nearby this gate was once The Galt's Tower (Figure 3.8), whose foundations were preserved, providing enough clues to conclude its functions. The name of the tower was taken from the nearby village Ungra (German: Galt) and, probably, it was administrated by them, proving that the fortress served a wider area than just the adjacent town. The identified building materials from the foundation do not come from the same source, therefore the tower underwent several 
additions, reconstructions, and changes. Along the same crenelated wall (Figure 3, between 8 and 14), in the past, there were several chambers that belonged to the local and regional officials, and also unpreserved wooden galleries and wall walks.

The Pentagonal Tower (Figure 2.14) is the most interesting defensive building of the fortress due to its original structure and functionality, including the sharp angle of the flanking tower which indicates north, therefore making its shadow a sufficiently accurate time indicator. It is not proved that the shadow was used to read the time, but it is possible, considering the fact that, before the $18^{\text {th }}$ century, the permanent residents of the fortress, would use the sun position to estimate the time (Maroși, 2015, p. 118). Another important aspect is that the tower was constructed to eliminate the blind spots of the two side walls and also to defend the vast ward of The Lower Fortress, through its dominant position.

Between The Pentagonal Tower and The Scribes' Tower (Figure 3, between 14 and 15), the wall is fitted with combat niches and the preserved foundation of the second wall shows that, in the past, there were several private storerooms, whose defence was assured by the owners in case of a siege. It is possible that, above these private storerooms, there was a wall walk or there were even wooden galleries. The Scribes' Tower (Figure 3.15) is a simple rectangular flanking tower with a mono-pitched roof, with separate entrance to the basement and the upper floors. This tower was used as a deposit for the local and regional archives and also as a working place for local clerks and officials. The tower has several loopholes and other firearms openings. The curtain wall between The Scribes' Tower and The Chapel (Figure 2, between 15 and 11) defend the southern part of the fortress, taking advantage of the high slope of the hill. Along this wall, in the past, there were private houses defended by the owners, in case of a siege. Today, only the windows and the loopholes of those houses can be observed on the curtain wall.

The Scouts' Tower (Figure 2.10) or, according to Borcoman (2010, p. 20), The Gresbig Tower, was built in the $15^{\text {th }}$ century and the name was given after a local personality. It is the largest and strongest flanking tower of the fortress, constructed to reduce the vulnerability of the topographically disadvantaged western walls. The wall between The Scouts' Tower and The Galt's Tower (Figure 2, between 10 and 8) keeps the defensive characteristics of the adjacent towers and, initially, the two were linked by a wooden gallery above which a covered wall-walk ensured maximum visibility. The entire defensive alignment was fitted with firearms openings, loopholes and probably machicolations (used to pour hot oil, water or stones out of). On the same alignment, there is The Scouts' Secret Gate (Figure 2.12), which was probably hidden by a false structure and defended by an overhanging brattice, accessible only with a ladder.

The Chapel (Figure 3.11) is a massive building with a mono-pitched roof, a strengthened exterior wall and firearms openings, built in 1650. The religious function is attributed due to the original inscriptions "God is our strength and confidence" (Borcoman, 2010, p. 20). This building belonged to the parish house. Besides this building, up on the hill, there are the ruins of The Thickened Tower (Figure 2.13), which is linked to The Pentagonal Tower with a defensive wall fitted with firearms openings. This topographically advantaged wall inside The Middle Fortress could be seen as a Zwinger wall with two Zwingers (the area between two defensive walls, used as a trap in case that the curtain wall would fall under siege).

In the worst case scenario, if The Middle Fortress, with all the defensive measures, would fall under siege, there is still a third chance of retreat to The Upper Fortress (Figure 2.C), which occupies the basalt cliff and benefits from an exceptional natural defence. The only vulnerable spot of The Upper Fortress was The Upper Gate and Tower (Figure 2.17), which was built with a heavy vertically-closing gate (portcullis), as shown by the existence of the vertical, narrow, 
hollow space built into the preserved wall of the tower. The gate was built in a harmonious way with the natural wall, strengthening the vulnerable points successfully, as it was observed by Charles Boner (1865, p. 244): "it was not well possible to say where nature ended and where the work of men's hands began." A prominent building stands out in the southern part of the cliff, one of the visible buildings which creates the so familiar skyline of the fortress and where was the seat of The Regional Administration (Figure 2.19). Starting from this point, the picturesque view of the town is revealed. The area occupied by The Upper Fortress is the oldest fortified part; even if the buildings are more recent, they are following the carved foundations of the older buildings. The preserved private houses from the $17^{\text {th }}$ century (Figure 2.20), with other preserved foundations, indicate that the fortress was inhabited. Through narrow pathways and stairs situated along the walls, one can reach the The Watchmen's House (Figure 3.21), which is built on the highest point of the cliff, at more than 120 meters above the town.

\section{Rupea Fortress before and after the rehabilitation}

The town of Rupea and its old administrative region - Scaunul Rupea (Ro)/ Stuhl Reps/Kosd (Ge)/ Kőhalom szék ( $\mathrm{Hu}$ - are distinguished by their cultural and historical value, supported by the multicultural environment; all the development or regression stages of the region were recorded during the expansion stages of the fortress, making it a cultural artifact with many significances for the history of Transylvania. Therefore, the fortress rehabilitation has aroused the interest of the population in the region and of the media, since its inauguration in June 2013, many positive and negative opinions have been published but the overall results were mirrored only by the large number of tourists. As we mentioned, the differences between rehabilitation and restoration can be seen and felt, a few details reveal the rehabilitation accuracy, such as the simple shed or gable roofs (Figure 4.A) and the tented roofs with steeply pitched slopes (Figure 4.B), which are more representative for the medieval architecture, but not in all cases. After rehabilitation (Figure 4.B), the ruins lost their romance, which reconstructions often lack, the atmosphere inside the fortress is resembling more a public space with too many benches, perfectly aligned trees on a greensward surrounded by white walls and red roofs (Figures 5 and 6 ).
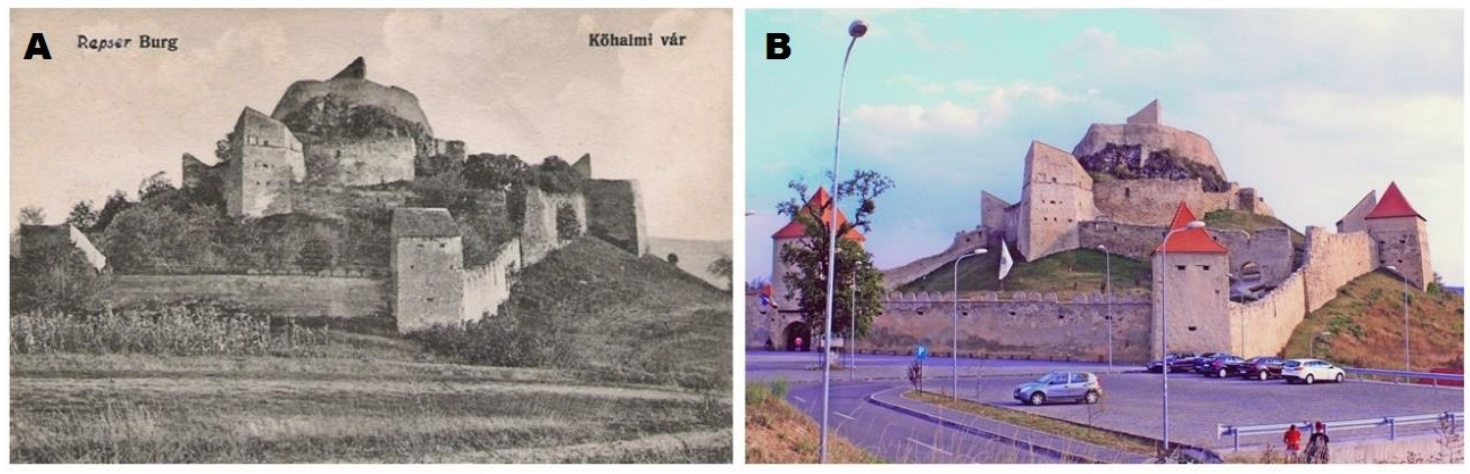

Figure 4: View over the north side of Rupea Fortress, A - before and B - after rehabilitation Postcard (1909) and photograph (2016) from the author's personal collection

We agree that if the investment would not have been made, the lack of conservation would have led to the irreversible degradation of the fortress (Figure 5.A) and the town would have missed the chance to harness the economic potential of tourism, but, at the same time, we 
encourage, in the future, a better management and a greater attention to details, supported by the profit of the fortress. Also a more detailed archival study should be carried out in the future.
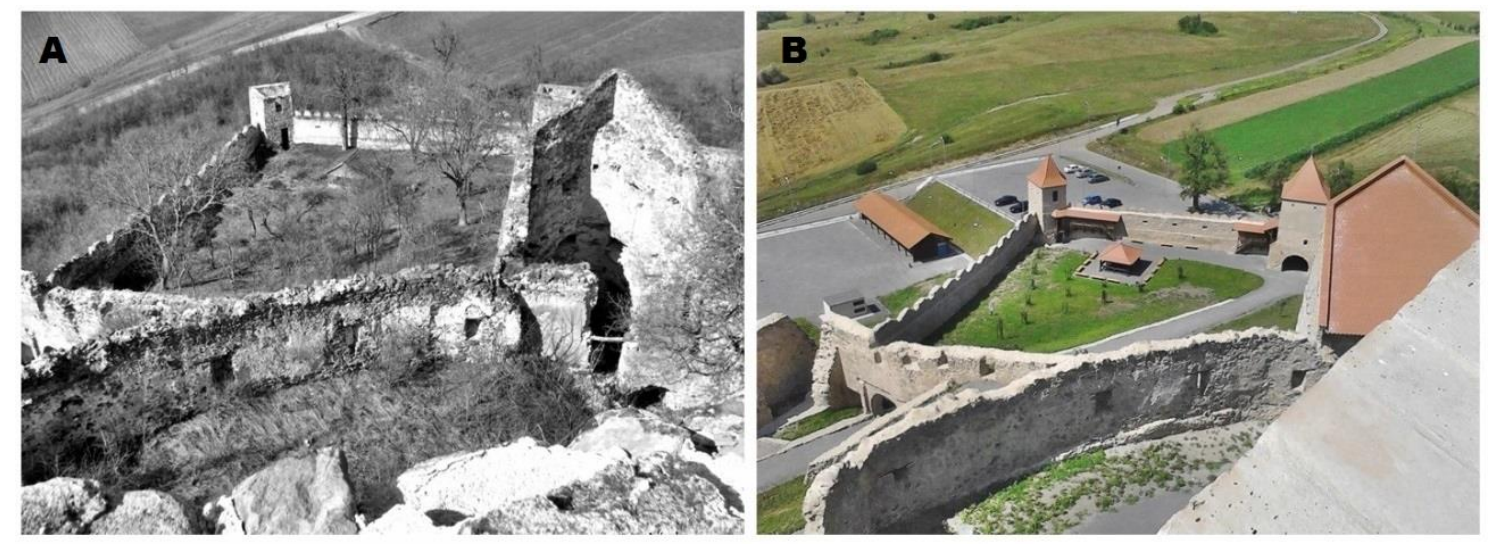

Figure 5: View over The Lower Fortress, A - before and B - after rehabilitation

Photos from the author's personal collection (A: 2002; B: 2014)

Excessive use of concrete during the rehabilitation raised suspicions among specialists outside the project. Many people have visited the fortress and even if the majority left the place with a good impression, those few specialists (archaeologists, historians, urban planners, architects, geographers, environmentalists, etc.) were not as pleased. There are some general causes for their dissatisfaction regarding the project and all ends with the highly invasive methods used in the rehabilitaion process: massive (monster) concrete blocks in the parking lot just a few meters from the historic wall, concrete injections in walls and foundations, inappropriate building materials and procedures (Figure 6). Yet, many did not see anything wrong in that.

As mentioned before, rehabilitation was focused on the technical side, considering that besides the architectural plans, other additional studies, such as a History and Archaeological Study, have not been completely made. This was also reflected in several unexpected archaeological discoveries during the excavations as part of the rehabilitation process, among which the pulleys of the movable bridge or draw-bridge of the The Main Gate (Figure 3.5) and a pit, originally with sharp stakes - known as "trou de loup" were found and buried back because the rehabilitation plans did not provided a solution to restore them. One reason for this reburial of archaeological discoveries was lack of financing (financing complying only with the initial plan).

The lack of thorough studies led the rehabilitation to a long list of unsolved or partially solved problems, which were temporarily forgotten due to the large number of visitors which exceeded by far the estimations. For every year, since 2013, the average number of visitors has been 60,000 , with an accelerated annual growth at the beginning and moderate in 2016, with the remark that numerous newspaper articles exaggerate the real numbers. In this way, the public opinion was influenced and important issues such as the unexpected discovery of the only preserved gothic wooden framing in the The Scribes' Tower (Figure 2.15), among other $17^{\text {th }}$ century foundations of houses, has been neglected. The lack of a guide or other informative panels let the visitors to pass along such significant items without drawing their attention and this way the general opinion about Rupea Fortress is focused on its emptiness; without the typical romantic environment of the ruins, the visitors perceive the space without the attributes of historical or cultural heritage (Figure 6). 

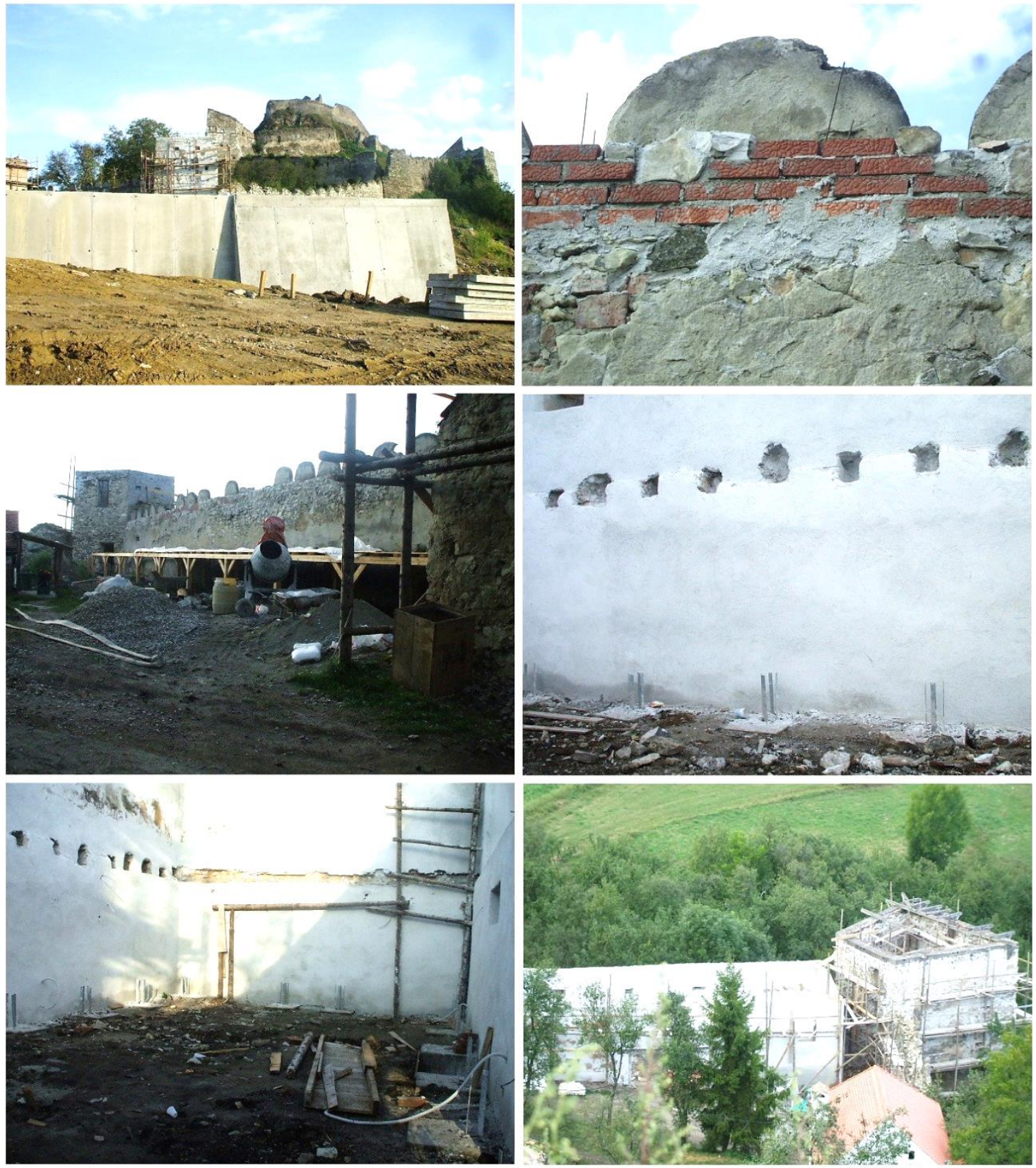

Figure 6: Details captured during rehabilitation (September 2010), underlining the invasive methods based on the extensive use of concrete in historical walls and foundations

Photos by Monica POPOVICI (September 2010)

Among the local government priorities, one is to increase the number of tourists and this objective can be achieved only if the investments will be directed to a detailed research and a more complete History and Archaeological Study through which the historical story of Rupea Fortress and the nearby town can be recreated and narrated by local guides. This way, the visitors will be aware about the historical and cultural significance of the place which they visit and they may be sufficiently impressed to recommend the fortress to others and even to come back in the future. Improvement should be done in the future and the ideal context would be that a part of the actions are affordable and funded by the profit of the fortress. 

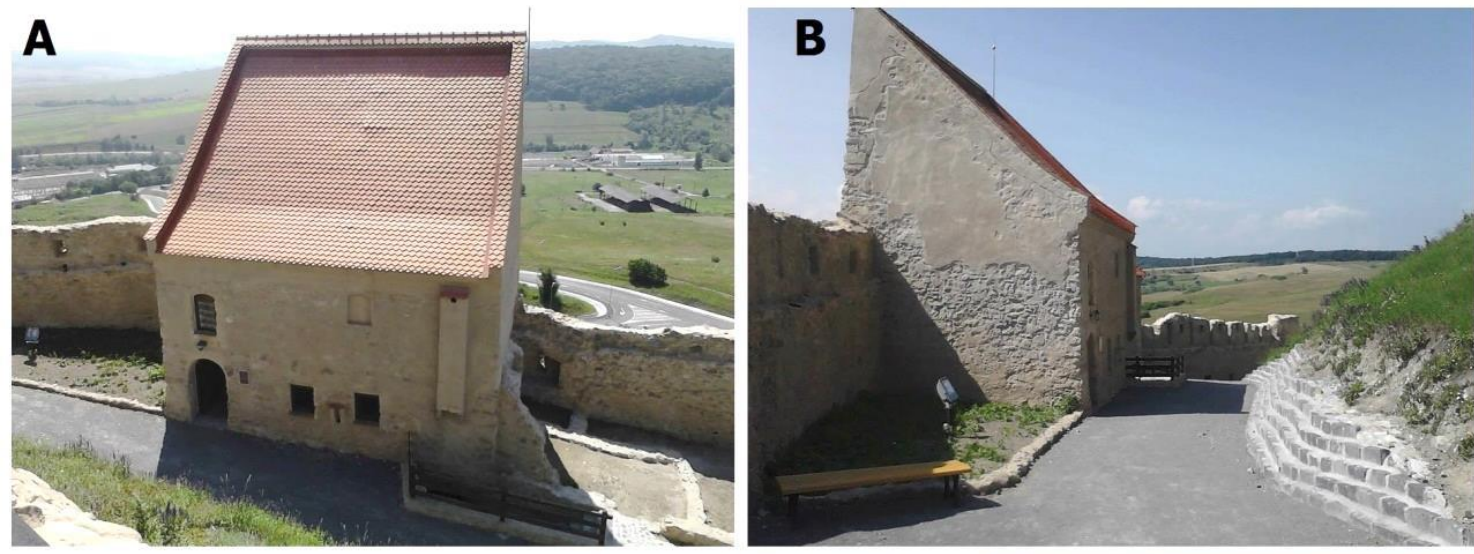

C

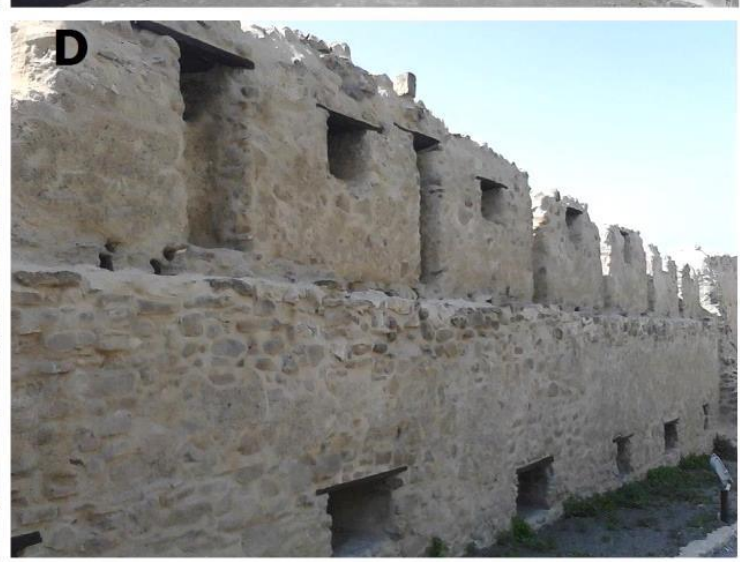

Figure 6: View over A, B - The Chapel, C - The Gresbig Tower or Scouts' Tower and D - details on the wall between The Gresbig Tower and The Middle Fortress Gate after rehabilitation

Photos from author's personal collection (2014)

Over the years, generation after generation, the fortress has become an inseparable part of the local landscape (Figure 7), an important landmark distinguished through its original shape and visibility, becoming part of the inhabitants collective memory, and a representation of their local identity beside their traditions, customs, crafts, and local cultural events.
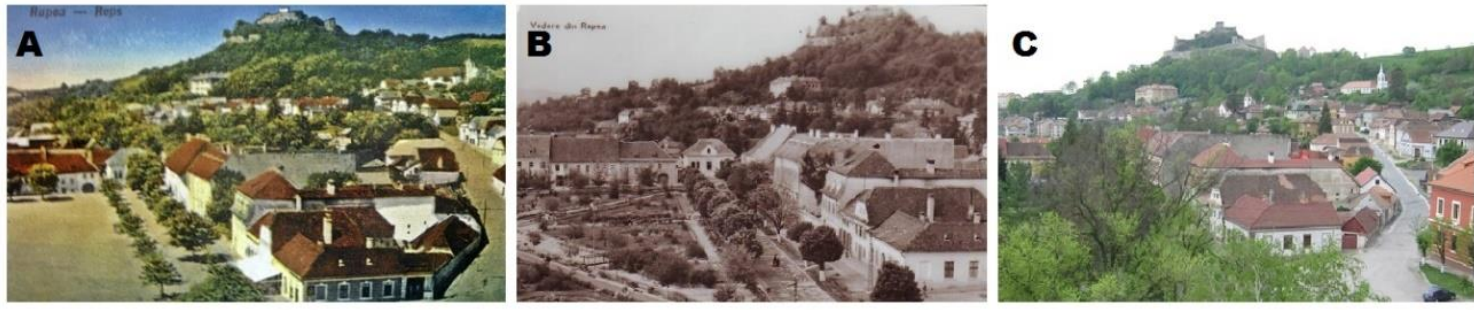

Figure 7: Functional reconversion of the central square in Rupea town, A - postcard from 1930, B - postcard from 1969, C - photograph taken in 2016

Postcards and photograph from author's personal collection 
Monuments, seen as cultural artifacts, reveal even more information about places and people, and the act of restoration should be recorded_carefully as Bristow $(2006$, p. 18) considers_. $[\ldots$.$] it$ must be stressed, historic buildings are important artifacts, which provide a wealth of data about past habits, manners, techniques, and aspirations. In some cases they may be the only documents left by a defunct civilization." Furthermore, the unsuccessful restorations of several monuments such as The Fortress of Feldioara, Mălăiești Castle or the controversial Fortress of Deva suggests the lack of specialised interdisciplinary studies and encourages even more the future approaches in this domain. These restorations were severely criticized by specialists in medieval history on journalism blogs as Think Outside the Box, The Mălăiești Castle being compared by Vladimir Agrigoroaei (2014) with a product of slum tourism, instead of cultural tourism, reflecting the low level of education of those who implemented the project and those visitors who appreciated this falsified representation of history.

\section{CONCLUSIONS}

Although this research is not as rigorous as a History and Archaeological study should be, it emphasizes the importance of studying historical buildings in order to preserve them for the future generations, in the most authentic way possible, so that their artifact characteristics and the stored information not to be lost in time. The efficient collaboration between local authorities, contracted companies and experts (architects, archaeologists, archivists, restorers, engineers, artists, historians, urbanists, geographers, geologists, chemists, etc.) should minimize the occurrence of errors and would create an environment in which smart solutions could be found, tested, and applied. Most often, restoration projects and studies are not transparent, or accessible to the public and usually reduce the social dimension of the restoration to a minimum, neglecting the historical and cultural aspect of the monuments in favour of their physical attributes and their commercial potential. Given these facts, we believe that these studies should be encouraged, improved, popularised and observed in the restoration process so that future generations can enjoy a well preserved monument due to our current efforts.

\section{REFERENCES}

AGRIGOROAIEI, V. (2014). About the Recent Death of Mălăieşti Castle. In: Think Outside the Box [Blog post]. Retrieved December 12 2016, from: https://www.totb.ro/monumentul-manea-despremoartea-recenta-a-cetatii-de-la-malaiesti/

BECKMANN, P., \& BOWLES, R. (2004). Procedures of Structural Appraisal. In: BECKMANN, P., \& BOWLES, R. (eds.), Structural Aspects of Building Conservation (pp. 37-87). Oxford: Elsevier ButterworthHeinemann.

BONER, C. (1865). Burgher Strongholds. In: BONER, C. (ed.), Transylvania: Its Products and Its People (pp. 228-247). London: Longmans, Green, Reader, and Dyer.

BORCOMAN, M. (2010). Aşezări transilvane. Rupea [Transylvanian Settlements. Rupea]. Cluj-Napoca: Academia Română. Centrul de Studii Transilvane.

BRISTOW, I. (2006). An Introduction to the Restoration, Conservation and Repair of Stone. In: ASHURST, J., \& DIMES, F. (eds.), Conservation of Building and Decorative Stone, $2^{\text {nd }}$ edition (pp. 1-19). Oxford: Elsevier Butterworth-Heinemann. 
CURINSCHI-VORONA, G. (1996). Sistemul categorial al restaurării [The Category System of Restauration]. In: CURINSCHI-VORONA, G. (ed.), Arhitectură. Urbanism. Restaurare. Discurs asupra istoriei, teoriei și practicii restaurării monumentelor și siturilor istorice (pp. 1-50). Bucharest: Editura Tehnică.

DECISION OF THE ROMANIAN GOVERNMENT no. 115/2013 Concerning the Approval of the Coats of Arms for the Towns of Rupea şi Victoria, Braşov County (in Romanian). Monitorul Oficial al României, no. 193 from May 42013.

FEILDEN, B. M. (2003). Introduction to Architectural Conservation. In: FEILDEN, B.M. (ed.), Conservation of Historic Buildings, $3^{\text {rd }}$ edition (pp. 1-37). Oxford: Architectural Press.

ILOVAN, O.-R., \& MAROȘI, Z. (2015). Leadership and Regeneration of the Transylvanian Villages in the Region of Rupea. In: BANINI, T., \& INCH F. (eds.), Semestrale di Studi e Ricerche di Geografia, 27(1), 63-70.

IRIMUŞ, I.A. (2010). Relieful: potenţial şi valorificare turistică [Landforms: Touristic Potential and Exploitation]. Cluj-Napoca: Risoprint.

LAW no. 5/March 62000 Concerning the Approval of the Plan for the Arrangement of the National Territory - Third Section, National Protected Areas (in Romanian). Monitorul Oficial al României, no. 152 from April 122000.

LMI Code, according to the Law no. 422/2001, Order of Culture and Religions (MCC, in Romanian), no. 2682/2003. Monitorul Oficial al României, Part l, no. 448 from June 242003.

MAROȘI, Z. (2015). The Relevance of Using Photographs in Geographical Research. Geographia Napocensis, 9(1), 109-119.

MAROȘI, Z. (2016). Redrawing Historical Illustrations in Research of Genuine Urban Features. Territorial Identity and Development, 1(1), 45-58.

MOUGHTIN, C., OC, T., \& TIESDELL, S. (1999). Urban Design: Ornament and Decoration, $2^{\text {nd }}$ edition. Oxford: Architectural Press.

MUTIHAC, V. (1990). Structura geologică a teritoriului României [Geological Structure of Romanian Territory]. Bucharest: Editura Tehnică.

NASSER, N. (2003). Planning for Urban Heritage Places: Reconciling Conservation, Tourism, and Sustainable Development. In: AKAR, G. (ed.), Journal of Planning Literature, 17(4), 468-479.

ORDER no. 562/2003 from November 20 2003, of the Ministry of Transport, Constructions, and Tourism (MTCT, in Romanian). Monitorul Oficial al României, Part I, no. 125 from February 112004.

SPOSITO, V.A., \& FAGGIAN, R. (2013). Systemic Regional Development - A Systems Thinking Approach. In: BAUMFELD, L. (ed.), Region als System - Theorien und Ansätze für die Regionalentwicklung, Informationen zur Raumentwicklung (pp. 2-12). Vienna: Bundesinstitut für Bau-, Stadt- und Raumforschung (BBSR). 